\title{
Designing for longevity
}

\author{
V. Straka \\ Department of Architectural Science, Ryerson University, \\ Toronto, Canada
}

\begin{abstract}
The design stage of a building project is very important. Design impacts the site, physical massing, material selection, potential reuse, and energy performance. This paper addresses issues of durability of building systems in relationship to the life of a building. The spatial planning and systems selection during the design stage, with particular focus on the sustainability and life cycle of systems and materials, are essential to the potential to prolong the building's and its components life by adaptive reuse or by dismantling for reuse at other location or component reuse.

Most buildings are designed by current codes to last 30 to 100 years at most. This means that a building built today will consume energy and resources for the replacement of its components and for its maintenance for at least the same time span. If no action is taken today, then our environment is at risk during this entire period, if not longer. It is very important to consider the impact on future generations of what is being done today. Considerations of life cycle evaluation and costing over the entire life of the building are the only reasonable way to evaluate a project. As the refurbishment of buildings has potentially the least environmental impact, it is important to consider the implications of designing at least some elements, notably the structure, to provide flexibility and potential for alternative use.

Keywords: design life, sustainability, cradle to grave, life cycle assessment, durability, adaptive reuse, component reuse.
\end{abstract}

\section{Introduction}

Over the past decade, severe weather conditions, such as hurricanes, tornados, storms, heavy rains, and unusual seasonal variations in temperatures have been increasing in number and intensity all over the world. A northern community in 
Alberta which relies on a winter road for transportation of all supply was, in 2006, for the first time completely cut off. Due to mild temperatures, the earth had not frozen. Frequent news from the Arctic over the last few years confirms that the ice is melting and cracking and permafrost is thawing, endangering the life of many communities. Even people who thought in the 1990s that the notion of "global warming" was just a scare tactic by environmentalists are slowly accepting that something is happening. Climate change is not a bad dream but a reality. Scientists have also become united on this issue as all global weather models predict occurrences of significant changes, with the most impacted areas being the Artic and Antarctica. The rise in greenhouse gas concentrations are the result of all our activities on this planet, from the food we eat, to the work we do, to the comfort we take for granted in our lives and leisure activities. Canada made a commitment to Kyoto agreement by reducing its greenhouse gas emissions by $6 \%$ based on 1990 level by 2010 but, in reality, emissions have been increasing by $1.5 \%$ per year since 1990 . Currently, greenhouse emissions stand $+20 \%$ over the Kyoto target.

Approximately $40 \%$ of Canada's annual national resource expenditure is consumed by the construction industry $\mathrm{CaGBC}$ [1]. The proportion is even larger for non-energy non-renewable minerals. In Canada, construction and demolition waste equals about $35 \%$ of the total waste stream in Canada CCA [2] representing $11 \mathrm{mega}$ tonnes in weight. This paper will look into possible improvements in which designers can improve the bleak statistics of construction industry.

\section{The design life of a building}

Buildings are designed to last a certain number of years, usually as specified by codes which primarily focus on design loads. Environmental loads (snow, rain, wind, seismic) are recorded on a regular basis, some even constantly, and these measurements are statistically processed to determine the design (specified) loads with a known probability of being exceeded in any one year NRC [3]. There are three types of structures. Temporary structures are usually in place for less than a year. Regular structures include commercial and industrial structures. In Canada, these are designed for loads with a 1 in 30 probability of being exceeded in any one year and with an expected life span of 50 years. Housing is also included as a regular structure and is expected to last 30 years. The third structural type includes important buildings such as government buildings, hospitals, and schools. These are designed for environmental loads corresponding to a probability 1 in 100 . However, this does not mean that they are designed to be in service for 100 years.

When considering the design life of a building, it is important to distinguish between its potential life and its useful life, the latter meaning that the building serves the same purpose as it was designed for. When a building is designed to fulfil a particular owner's needs, future needs are usually taken into consideration, but these hardly ever exceed 10 years. It is hard to predict what will happen even in five years. Our business practices have changed and will 
continue to evolve as technology advances. Today, business can be operated from home, product support inquiry from a Canadian customer can be rooted without any problem to India, and, as a result of globalization, manufacturing operations are moved to places where the labour force is cheap. Other examples over the past decade include the drastic change in sizes of mainframe computers and the way data and information is stored. It appears that current trends demand fewer people in the office, smaller space, and less storage. There are many changing and unpredictable parameters and this is possibly why codes remain concerned with loads only.

On the other hand, the document Guidelines on Durability in Buildings CSA [4] addresses design issues related to the creation of durable buildings. The selection of building components to comply with design requirements determines their service life and impacts overall durability of a building. The Guidelines are very important as they try to rationalize criteria for determination of durability and as they recognize the importance of appropriate maintenance during the life of the component. Unfortunately, this document gives recommendations only.

When referring to the life of a building, it is necessary to separate permanent elements, such as structure, from elements which can be replaced. Today, many buildings have structural skeletons which are enclosed by an independent system connected to the structure. In addition, there are other systems such as mechanical (heating, cooling, ventilation, hot water), electrical, life safety, and communications, which typically have a much shorter life and which are significantly impacted by technological advancements. It is therefore necessary to consider a building as a series of systems, each having a different lifespan. The building structure with the greatest life potential will last 30 for more than years. Communications, however, may last only a few years.

\section{Environmental Issues}

The environmental issues address the impact of a building on the environment as well as the impact of a building on its occupants/ users.

\subsection{Impact of the project on the environment}

Any construction project has a serious environmental impact, one which spans the period of time from a site development to a potential demolition. The site development, construction process, and production and delivery of materials result in the disturbance of local ecosystems on the actual site or, due to natural resources extraction, off-site pollution, demands on energy, waste generation, and greenhouse emissions. During its life, a building demands a continuous supply of energy for heating, cooling, lighting, and water provision, and it requires maintenance. This stage of the building's life requires the greatest amount of energy and it is associated with the largest greenhouse emissions.

A typical office building (the minimum energy standard compliance) in Toronto consumes $89 \%$ (with very little variation resulting from the material selection for the structural system) of the total embodied energy during its 
operational life of 60 years. Another $6.5 \%$ is consumed on maintenance over the same period Straka [5]. The initial embodied energy (related to materials and the construction process) is under $4.5 \%$. Hence, the very simple conclusion can be drawn that all aspects of the design process must address issues of durability, minimum energy consumption, and energy efficiency. It should be noted that these figures vary depending on the climate and use of the building Straka [5]. At the end of its life, if a building is destined for demolition, the main impact is the creation of waste. Otherwise, the embodied energy associated with this process is very small, much less than $0.5 \%$ Straka [5]. The "cradle to grave" stages of a building's life are now completed. But, importantly, there is a potential for reuse. With the process known as adaptive reuse, the building can be put to an alternative purpose. With component reuse, some of the components can be processed for reuse on another project or reprocessed materials can be created in some other form. If the building is renovated, there is considerable reduction in environmental impact related to construction material and process. LEED ${ }^{\mathrm{TM}}$ CaGBC [1] and other environmental rating systems encourage adaptive reuse, salvage and refurbished component reuse, and use of materials with recycled content. These rating systems are largely responsible for the increasing interest in this area.

\subsection{Indoor environment}

Buildings not only impact the environment but also their occupants. The issues associated with creating a healthy and comfortable indoor environment have been garnering increasing attention Hydes et al. [7] and are becoming a design consideration. Again it is important to note that environmental rating systems such as LEED ${ }^{\mathrm{TM}}$ embrace these issues. In order to understand the significance of indoor environment, it is important to realize that operating a business, i.e., paying people salaries, over the life of a building becomes by far the greatest expenditure. Any additional expenditure or loss in productivity has a significant impact on the operational cost. If the total cost of a project is considered, it can be broken into three major components: capital expenditure, maintenance and operating cost, and business operating cost. It was found [6] that the ratio of capital expenditure to maintenance and operating cost to business operating cost for an office building is 1:5:200. It is expected that this ratio does not vary significantly for buildings where humans are part of the process of wealth creation. This ratio clearly points out the significance of indoor environment. If the indoor environment is healthy, occupants are comfortable, in charge of controlling their environment, connected to outside and daylight, they feel and perform better. When these conditions are present, occupants are less likely to be absent from work or be sick, and more likely to be productive. Very importantly, with proper indoor environments, it will be easier for businesses to attract and keep the best employees.

Clients seem to be concerned about capital expenditure and how to decrease construction and design costs, but are not aware that these savings are not significant in the contexts of the total expenditure during a building's life. The design cost is typically less than $10 \%$ of the capital expenditure but the design 
team controls an outcome two-thousand-time more significant financially. This indicates that the design team has the most significant role in achieving these financial goals.

\section{Issues related to durability}

\subsection{Structural elements}

The structural elements of a building are mainly enclosed and protected from weather and de-icing chemicals. If the building is constructed following the current best practices for construction techniques there are very few problems with structural elements. Therefore they are usually found in excellent condition: concrete is unspalled, steel is not rusted, and wood is dry with no signs of rot. Thus, these elements are suitable for adaptive reuse-meaning that the structure can be adapted and refurbished for new uses - or for component reuse, meaning the incorporation of used components into a new construction at a new location. It was noted that the design loads are for 30 or 100 year environmental events but this does not mean that a given structure could not last for 100 or 200 years, a relatively short time frame when considering the passage of human history. The reuse of a structure or of its components is very viable. However, there are some potential obstacles related to both reuse processes. Codes generally favour new construction NRC [3] but make provisions for buildings that do not comply with the current code. As the codes do not outline procedure to determine the suitability of a structure or component for reuse, it is up to building officials to determine requirements from the design team. Obviously, this situation may hinder the process of adaptive reuse.

\subsubsection{Design strategies}

There are no major problems with regard to durability of structural materials if standard best practices for a specific material are followed. As mentioned before, structural elements are not usually exposed (parking garages is one exception) and therefore usually do not require any maintenance. However, there are many design issues not related to durability which are essential and which must be addressed. These are primarily related to detailing of connections between components for easy deconstruction.

\subsection{Building envelope}

Building envelope elements are designed for lower environmental loads due to their typically shorter life span. The performance failure of any building envelope component is not catastrophic but has serious social, health, and economic issues. Leaky condominiums demonstrated the great social impact of problems related to moisture infiltration in the building envelope. These problems caused hardship to some property owners and health hazards from mould formation for others. The problems were not related to lack of performance of any of the components but resulted from the combination of architectural design, detailing, and workmanship. The design and detailing of a 
building must incorporate provisions for replacement of building envelope components.

Durable cladding results in savings in natural resources and energy, in waste reduction and disposal, in maintenance, and often in savings over the life of a building. The initial cost of durable components is often high, but the additional benefit is often in better performance, leading to a more favourable life cycle analysis. Premature failures lead to reduced performance which is often related to increased energy use. At the end of a building's life, durable components may be sold for reuse.

\subsubsection{Design strategies}

The following design recommendations are based on the assumption that each component of cladding is designed for an appropriate set of environmental loads.

- Analysis of alternative systems, including environmental and deterioration analysis.

- Documentation of the selection process, including evaluation criteria and life cycle cost analysis.

- Design review incorporating the building envelope components. There are architectural design implications which come from the selection of a particular cladding, i.e., EIFS must have sills and overhangs.

- Detailing of the building envelope. Details should go beyond the composition of a system as they are standard and well defined. The focus should be on detailing of interfaces between different components, including the overall analysis on how the building envelope details fulfill its function.

- Detailing of system components for easy access for maintenance and replacement. Cladding systems often do not allow replacement of components but the entire system must be replaced (e.g., window replacement requires the replacement of the entire cladding system). Detailing should be sensitive to the issue of which tools are required for component replacement. Generally, standardization will promote replacement, reuse, and separation for recycling.

- Communication and discussion of design intent to the contractor, fabricator, and installer. Knowledge of local construction practices is a very important part of the process. The very best detailed system can result in poor performance if the detail is not understood on the construction site either because the intent is not clearly documented or it departs from the local norm.

- Development of the maintenance plan.

\subsection{Mechanical, electrical, and communication systems}

These systems have by far the shortest life as they are significantly impacted by advances in technology and because many have moving components. All equipment requires regular maintenance to ensure that it performs at the optimal level. It is often necessary to replace equipment before the end of its life, either 
because the repair costs are too high or because better and more efficient equipment is available.

\subsubsection{Design strategies}

It is very important to accommodate mechanical components in a building in the most flexible way, allowing for easy access to maintenance, replacement, and changes in technology. Obviously, a minimum amount of mechanical equipment is better and more sustainable. In contrast to the case of building envelopes, replacement costs are commonly incorporated into maintenance budgets.

\section{Design issues}

The most important factor in prolonging the life span of buildings and minimizing their environmental impact is the design. Architecture, spatial planning, and flexibility determine a building's potential for reuse. The health of a building is related again to design and there are economical constraints Lucuik et al. [8]. Below is a list outlining important design considerations:

- Architectural design combined with massing of programs determines a building's shape and the surface area exposed to the environment. This impacts energy demands. Also, architectural design has a serious impact on the performance of building envelope components.

- Spatial planning of a building is of utmost importance. Spatial planning determines the penetration of daylight into the interior, the functionality of passive systems, and adaptability for many potential layouts for interior use.

- The structure should be designed for appropriate occupancy loads and should include potential for expansion. Around the perimeter, it should accommodate a variety of cladding system loads and include flexible penetrations between floors for mechanical/ communication services. This is very important for the future reuse of buildings. Structure is related to the shorter life span of mechanical equipment and to changes in technologies.

- Detailing of the attachment of cladding to the structure should account for ease of access and replacement.

- The building envelope should be detailed in a way which allows for component replacement.

- There has to be a benefit, social or economical to improved design and environmental

\section{Case studies}

\subsection{BMW building}

BMW's new flagship store opened in downtown Toronto in the autumn of 2003. It is located on a highly visible site by the Don Valley Parkway (the DVP, a major traffic artery) and the Don River. The site was occupied previously by an existing 1960s steel-framed office building (which was extended in the 1970s), and was classified as a "brownfield site" requiring extensive remediation and an 
environmentally sensitive area, flood plane of the Don River. Any new construction would have to abide by stringent setback regulations established by the Toronto \& Region Conservation Authority and would have pushed a new building farther away from the DVP and made it impossible to retain the same visibility as the existing structure enjoyed. Thus, it was agreed to keep the original footprint and adapt the existing structural frame and redesign its exterior and interior and create an addition to house the service department.

The structural system of the existing building was a one-bay steel frame with hollow precast concrete panels spanning 16 feet between the frames. With the decision to keep the existing footprint, the building was stripped down to its structural steel skeleton with precast concrete slabs. Availability of drawings for the original building from the 1960s as well as for the two-storey addition from the 1970s made it possible to identify accurately the structural properties of the steel. Visual inspection was required to confirm the actual quality and steel properties were confirmed by tensile tests. It was determined that the existing structure, though sound, would need strengthening to meet current building code seismic provisions and change of occupancy from office to retail. This resulted in strengthening of all beam column connection to act as rigid frames by welding of additional t's or plates. Also some columns in the area of new two storey space and beams required strengthening.

The project, both innovative and of high quality, was completed in just over 2 years. The reuse of steel resulted in few complications and produced little ambiguity.

\subsection{MEC}

Mountain Equipment Co-Op (MEC) is a well-established retail company operating as a membership co-operative and supplying quality outdoor equipment and wear in Canada for over 30 years with retail facilities in 10 locations across Canada-from Vancouver to Halifax. MEC prides itself on its reputation as a "Green Company". It adopted a corporate policy which amongst others emphasizes leadership for a just world, social and environmental leadership and strives for a healthy planet. As well as their business operations, the construction of their buildings follows strict guidelines for sustainability. Green roofs, composting toilets, daylighting, recycled/reused materials, radiant floor heating, efficient heating/cooling and energy saving measures are just some of the features found in some of their buildings.

The Winnipeg project was innovative in its construction and design. The project was a collaborative effort and followed an "integrated design process". Meetings were held and feedback from the public was sought and equally valued as that of the stakeholders. In this way the community was engaged in the importance of material reuse. Team members worked together from the very start and developed a conceptual design approach in 6 intensive workshop/design sessions. MEC's values and goals were clear and the architects and owners worked collaboratively to achieve the "greenest" building possible. The building is located on a small parcel of land in downtown Winnipeg which had 3 existing buildings on it. It was decided to reuse the buildings as much as possible. Two of 
the three structures were unsuitable and deconstructed, and materials found in these buildings was reused in the new building, while the remaining structure of the third building was retained and redesigned. The $960 \mathrm{~m}^{2}$ store uses a wide variety of materials - reused and new showcasing sustainable features in a modern facility. Materials not incorporated into new construction were used elsewhere $(300,000$ bricks were cleaned and given to Habitat for Humanity for reuse). The project achieved a gold rating from $\mathrm{LEED}^{\mathrm{TM}}$.

\section{Conclusions}

The above two case studies demonstrate two different ways of prolonging the life span of buildings. It is important to design all future projects for adaptive reuse potential, considerations of environmental impact, and underlying health issues related to a building's indoor environment. Durability of building systems and their components is important as it conserves natural resources for replacement and maintenance and decreases the amount of waste. Besides environmental issues, durability has a serious impact on indoor environments. A leaky building envelope may result in a draughty indoor climate and in moisture retention within the walls which may support mould growth. Unfortunately, these effects are not easily measurable. During the design process, they may be neglected but they may have a serious impact on business operating costs. Economically, life cycle cost evaluations should be used to support system selection, but it is important that the analysis include other benefits associated with better performance, such as energy consumption and greenhouse emissions. Durability is very strongly associated with a building's life span. It has very little impact on the reuse of buildings and the extension of their life beyond design life.

The most important factors in prolonging building life are good design, flexibility, adaptability, and value of the building (architectural, reputation, and residual value).

\section{Recommendations}

It is essential to prolong the life span of buildings as this will reduce the environmental impact of construction. Very importantly, design issues have to be addressed as these have the major impact on building reuse. It is not only the architecture which distinguishes one project from another, but also the building's reputation. Is the building "sick"? What is the quality of the interior environment? What is the potential for adaptability? Design issues are still underrated perhaps because of the insignificant cost of design and the lack of relationship of design issues to indoor environments. In order to move forward, it is essential that design issues be addressed and that clients become educated about their investments. It is important that environmental strategies are tracked and their performance evaluated, including the comfort of occupants. In order to progress in this direction, it is important that the following observations be taken into consideration: 
- Improvement in design and indoor environment will not occur unless there is documentation which allows for evaluation of occupants and for performance surveys of buildings. It is important to educate clients that a post-occupancy survey is critical in determining the parameters for future design. It is not possible for designers to improve their designs unless they have feedback from practices they implemented in the past. As design cost is not associated with performance, neither designers nor clients who would accrue additional cost are interested in taking these steps. However, it is essential to improvement in the construction industry to define parameters related to performance, which could impact design.

- Improvement in design strategies for effective green buildings is related to input from performance evaluation of existing buildings. This is a weak link because there is very little information on how green buildings perform and on how they are related to indoor environmental quality.

- Education of clients is of outmost importance as it can assure that their goals for achievement of efficient and profitable business are met while the environmental conscious design was implemented.

- Designers can move forward only if they are aware how their design perform in practice.

\section{References}

[1] CaGBC, LEED Canada NC v1.0, Canada Green Building Rating System, Canadian Green Building Council, Ca, 2004. www.CaGBC.org.

[2] CCA, A Best Practice Guide to Solid Waste Reduction, Standard Construction Document CCA 81, Canadian Construction Association, 2001.

[3] NRC, National Building Code of Canada, National Research Council, Ottawa, Ca, 1995 and 2005.

[4] CSA, CSA S478-95 (R2001) - Guideline on Durability in Buildings, Canadian Standards Association, 1995 (R 2001).

[5] Straka, V., Sustainability in Construction Industry. Proc.32nd Annual General Conference of the Canadian Society for Civil Engineering, CSCE, Saskatoon, Saskatchewan, Canada, GC-269, 2004.

[6] MacMillan, S. editor, Designing better buildings, E \& FN Spon, London, UK, 2004.

[7] Hydes, K., McCarry, B., Muller, T. \& Hyde, R., Understanding our green buildings: seven post occupancy evaluations in British Columbia. Closing The Loop Conference, Windsor, UK, 2004.

[8] Lucuik, M., Trusty, W., Larsson, N. \& Charette, A business case for green buildings in Canada, Morrison Hershfield \& Canada Green Building Council, Ottawa, 2005. 